\title{
Subjectivity and Objectivity in Science: An Educational Approach
}

\author{
Constantina Stefanidou, Constantine Skordoulis \\ Department of Primary Education, National and Kapodistrian University of Athens, Athens, Greece \\ Email: sconstant@primedu.uoa.gr
}

Received 29 July 2014; revised 4 September 2014; accepted 11 September 2014

Copyright (C) 2014 by authors and Scientific Research Publishing Inc.

This work is licensed under the Creative Commons Attribution International License (CC BY). http://creativecommons.org/licenses/by/4.0/

(c) (i) Open Access

\begin{abstract}
The subjectivity and objectivity of science are strongly associated to the nature of science, which is part of science education curricula worldwide. The issue under research is how an epistemological issue, like objectivity and subjectivity in science, could be introduced in science classes, so as to reflect the most realistic image of science. Following this line in the present study, concepts were related to what students and teachers should know, science education research and policy documents were explored, and current views within the philosophy of science were briefly summarized. We propose a distinction between the partially subjective scientific process and the rather objective end result of scientific inquiry as a schema promoting better understanding in science education. Intersubjectivity and critical transformation are then proposed as concepts which can enhance this schema. The history of science provides a suitable framework for teaching these ideas in science classes.
\end{abstract}

\section{Keywords}

Nature of Science, Science Education, History of Science

\section{Introduction}

Nature of Science (NoS) constitutes an integral part of the scientific literacy that science education aims to impart to both students and teachers. It is widely held in the science education community that a sophisticated attitude toward science should also encompass an idea of the subjective character of science. Additionally, the extended influence of constructivism and epistemological relativism, both reactions against some kind of "positivism", have made it unclear what teachers and students should understand about objectivity and subjectivity in science education. It is one thing to accept that there are social and personal factors in the scientific practice that may influence the process, quite another to uncritically assert that subjectivity permeates the entire scientific 
endeavor, including both practice and output. This study seeks to offer a brief overview of the topic and propose a suitable framework for teaching the subjectivity and objectivity of science.

Two main approaches have been followed when discussing objectivity in the context of science. In the first approach, objectivity is related, independently of any observer, to the true existence of objects and phenomena: this is an ontological view supported by realists. In the second, epistemological, approach, objectivity characterizes scientific knowledge and is perceived in opposition to the term subjectivity. In this context, the term subjectivity concerns the influence of social background and personal commitments on the process of knowledge acquisition. Clearly, it is not easy, or indeed possible, to keep these two views distinct. But for the purposes of this research, our discussion of the notion of the objectivity of science in a science education context focuses on the epistemological rather than the ontological question.

In order to teach and learn about the NoS Duschl proposed "the two faces of science" (Duschl, 1990: 9). The "first face" is the processes of science which include the methods employed in the collection, analysis, synthesis and evaluation of evidence. The other face includes the products of science, the scientific knowledge: facts, principles, laws and theories. The idea that the processes of science involve social and cultural influences is rather prevalent in discussions of the first face, and it is usually taken to insinuate the subjective character of scientific knowledge, which is the "second face" of science. Our aim here is to draw attention to the differences between the scientific process, which includes subjective elements, and scientific outputs, which are arguably objective due to peer reviewing and critical testing. The study is a theoretical research, methodologically based on literature review. In order to justify the above mention research purpose, we analyze and compare the correspondent literature on science education documents, science education research and philosophy of science. Finally we propose the notion of intersubjectivity and an episode from the history of science, namely Gilbert's work on electricity, as a means of highlighting and providing instruction relating to subjectivity and objectivity in science.

In Section 2 we attempt to identify implicit or explicit references to the subjective and objective NoS in the objectives of policy documents. The most prevalent view is that while science is culturally and socially embedded, it also enjoys the virtue of objectivity. This is something we fully agree with. It would therefore seem useful to discuss how scientific output ends up being rather objective despite the several factors that influence scientific practice.

In Section 3 we present views on the subjectivity and objectivity of science from the field of science education research. They vary in the sense that some of these views about the role of bias in science are explicit, while others are insinuated. A mainstream view shared by researchers in science education is that science is a culturally and socially embedded activity. A range of factors, such as scientists' personal beliefs and their socio-cultural milieux influence science to different degrees (Lederman, 2007; McComas, 2002; AAAS, 1993). A minority of researchers do not recognize the socio-cultural milieu as relating to the process whereby scientific knowledge is constructed (Kimball, 1967). Of course, the role played by social and other factors in science is a longstanding issue not only in the science education arena but also in philosophy. In fact, questions of how and to what extent personal and social factors influence science are situated at the centre of epistemology. The views of philosophers of science on the topic could undoubtedly provide a concrete base for discussion of the objectivity and subjectivity of science.

In this spirit, in Section 4 we consider some of the philosophical views on subjectivity and objectivity in science in order to form a more complete picture of the issues involved. After this brief discussion of educational and philosophical views on the issue, a modest conclusion emerges: the notion of intersubjectivity could facilitate understanding of the subjectivity and objectivity of science. While the scientific process is influenced by cultural and personal factors due to practitioners' background and bias, scientific output maintains a certain degree of objectivity and impartiality due to the critical testing conducted by the scientific community and to intersubjective agreement.

In Section 5, an episode from the history of science, namely Gilbert's work on electricity, is proposed as appropriate for highlighting and providing instruction in the differences between the subjectivity of scientific practice and the objectivity of scientific output.

\section{2. "Objectivity in Science" in Policy Documents}

The issue of objectivity and subjectivity in science is part of the so-called NoS which has a prominent place in 
any curriculum or set of standards that aims at scientific literacy (NGSS, 2013; NRC, 2012; AAAS, 1993; Curriculum Development and Supplemental Materials Commission, 2004; NRC, 1996; Ministry of Education, 1993). In the international science education documentation, the concepts of subjectivity and objectivity in science are implied rather than explicitly stated. For example, among other things, both elementary and secondary school students should be acquainted with the factors that play a role in the making of science, which include social, cultural and economic factors. The image of a science "unspoilt" by factors which increase its bias has long been refuted, so students at all levels are asked to familiarize themselves with the concept of science as a social endeavor. Regarding $12^{\text {th }}$ grade students, the American Association for the Advancement of Science (AAAS) suggests that they should know that "The direction of scientific research is affected by informal influences within the culture of science itself, such as prevailing opinion on which questions are most interesting or which methods of investigation are most likely to be fruitful. Elaborate processes involving scientists themselves have been developed to decide which research proposals receive funding, and committees of scientists regularly review progress in various disciplines to recommend general priorities for funding” (AAAS, 1993: 13). Regarding $8^{\text {th }}$ grade students, they should know that "Scientists know about the danger of prior expectations to objectivity and take steps to try and avoid it when designing investigations and examining data. One safeguard is to have different investigators conduct independent studies of the same questions” (AAAS, 1993: 12).

According to the recently published Next Generation Science Standards (NGSS, 2013), developed by the National Research Council (NRC), the National Science Teachers Association (NSTA), Achieve and AAAS: "Scientists' backgrounds, theoretical commitments, and fields of endeavour influence the nature of their findings" along with the fact that "Science and engineering are influenced by society". Such standards highlight the sociocultural factors and values involved in science which play a certain role in the construction of scientific knowledge.

At the same time, science is presented as enjoying the privilege of objectivity, mainly because of its so-called "scientific method". In the NGSS it is explicitly suggested that middle school students should learn that "Science investigations are guided by a set of values to ensure accuracy of measurements, observations, and objectivity of findings", while for high school students it is suggested that "Scientific inquiry is characterized by a common set of values that include: logical thinking, precision, open-mindedness, objectivity, skepticism, replicability of results, and honest and ethical reporting of findings". The empirical character of science makes it sound certain and objective. At the same time, a whole branch of philosophy, the sociology of science, challenges this same objectivity.

In the sphere of science education notions of subjectivity and objectivity in science seem to be still anything but resolved. What remains unclear is what exactly students should conceptualize about the "subjectivity of the objective science" or "the objectivity of the subjective science". A distinction between the subjective character of the scientific process and the rather objective character of the product of this process, which is scientific knowledge, would seem helpful here. The next section presents science educators' views on the topic as a means of sketching in the issues involved.

\section{3. "Objectivity in Science" in Science Education Research}

"Does the generation of scientific knowledge depend on theoretical commitments and social and historical factors?” (Eflin, Glennan, \& Reisch, 1999: 109). Although the majority of the educational community agree that social and historical factors, as well as theoretical commitments in the sense of a scientist's personal background and adherence to a particular theory or conceptual scheme, play some role in science, there is still a range of views about their nature, strength and implications. Regarding how the social influences the scientific, views range from those which associate sociality with the subjectivity not only of the scientific process but also of knowledge itself (Lederman, 2007; Osborne, Collins, Ratcliffe, Millar, \& Duschl, 2003; McComas, 2002; Burbules \& Linn, 1991), to those who do not even mention social influence (Kimball, 1967). A large part of the community of science educators does not necessarily distinguish the subjective character of the research activity from the rather objective character of the resulting scientific knowledge, preferring to generalize about the personal and social factors that can influence science.

Lederman (2007) argues that just as citizens' and students' interpretations of observed phenomena are influenced by their beliefs, values and previous knowledge, so too are those of scientists. In the same study he claims something which cannot be disputed; namely that students should come to realize that science, as a human activ- 
ity, is socially and culturally embedded. In another paper, however, he adds that "It is this individuality [of the working scientist] that accounts for the role of subjectivity in the production of scientific knowledge" (Lederman \& Abd-El-Khalick, 2002: 100). In the same paper, Lederman elaborates his claims on the subjectivity of science and states that scientists do not conduct absolutely objective observations, do not reach objective conclusions and do not evaluate new evidence objectively. Although some members of the community echo these views (McComas, 2002), the statement that "scientific knowledge is partially subjective" (Lederman, 2007: 834) needs clarification. How does the fact that scientists are influenced by their beliefs and previous knowledge make scientific knowledge subjective? Is it characterized as subjective because of its tentativeness or because of its dependence on personal values? And if the characterization is due to its dependence on personal values, the question arises of whether these values influence the scientific knowledge produced by the scientific investigation, or just the investigation itself-if the two can be distinguished, that is.

In the same spirit, McComas, Clough and Almazroa (2002: 14), in their attempt to support the inclusion of NoS courses in science teachers education programs, claim that "some of the resistance to conceptual change theory among classroom teachers arises from the mistaken notion that knowledge of the natural world is completely objective-existing independently of the searching individual”. In this research the authors characterize as "mistaken" a legitimate epistemological stream, namely that of scientific realism, aiming at an epistemological stance which will facilitate teachers' conceptual change. The point is what our students should learn about the objectivity of science. Particularly, after all the factors that have played a role in the formation of a scientific theory or model, how plausible is it to claim that a certain model or theory is subjective? A well-known example from the history of science may help—that of Coulomb's law for electricity. Specifically, so deeply influenced was Coulomb by Cavendish's and Priestley's conjectures about the interaction between two electrically charged bodies, and so profoundly theory-laden was his experiment, that Heering (1992) claims that he formulated the law not as a result of the experimental measurements from his torsion balance experiments but rather in the light of theoretical considerations. So, is Coulomb's law subjective? Although McComas et al. (2002) have a point when they claim that scientists cannot be absolutely objective for several reasons, including theory-laden observations and their allegiance to a certain paradigm, the question raised is whether an individual's subjectivity is strong enough to challenge the objectivity of the scientific product. Moreover, in the same study they recognize: "Items such as... the objectivity aspect of science... are important to students' understanding" (McComas, Clough, \& Almazroa, 2002: 49). In other words, it is necessary to introduce students and teachers to NoS as it really is, trying not to distort its image one way or another.

Millar and Driver in their study "Beyond Processes" present a critical review of the assumptions which underpin what is referred to as "process of science". In this research they support learning approaches which view "knowledge as personally and socially constructed, rather than objective and revealed; theories as provisional, not absolute" (Millar \& Driver, 1987: 57) as good alternatives to the traditional and old-fashioned picture of science. At the same time, they implicitly claim that social mechanisms protect the objectivity of science: "This (science) may involve empirical work in laboratories but it also encompasses broader considerations such as... the social mechanisms whereby knowledge becomes validated by communities of scientists..." (Millar \& Driver, 1987: 58). The validation by scientific communities is what increases the impartiality of science. Although the literature avoids specific definitions of objectivity and subjectivity in science, there is a common trend to relate objectivity to the independence of individual scientists' views and social factors, such as profit (Matthews, 1993; Kragh, 1998; Ziman, 1996). Another common feature of the objectivity of science is supported by its relation to intersubjective agreement, although this is not explicitly stated. Thus, after several discussions on a certain scientific topic, scientists come to an agreement which transcends their individual personal background, political ideas and socio-cultural milieux. This agreement is the result of thorough experiments and their connections to several interpretations, as well as to the transformation of different perspectives (AAAS, 1993; Ziman, 1996; Kimball, 1967).

Matthews recognizes the influence of social milieux in knowledge production, but tends to distinguish the process from the product. In his own words: "The fact that knowledge is humanly constructed does not entail that knowledge claims cannot be true, nor should the creations of science be tied to 'sensory inputs' in the way constructivists often do" (Matthews, 1993: 367). In the same spirit, Kragh, expressing his disagreement with both positivism and constructivism, cautions that although "the positivistically coloured conception of science that is still the core of most science education is clearly unsatisfactory, we should rather be cautious about characterizing as social or socially constructed all of scientific knowledge” (Kragh, 1998: 241). In the same study he 
rhetorically asks if a science teacher should correct one of his or her students who experimentally concluded that the boiling point of water is $54^{\circ} \mathrm{C}$. The boiling point of water is about $100^{\circ} \mathrm{C}$, presenting small variations depending on the pressure. Scientists have tested and fully accepted this particular piece of knowledge, the boiling point of water, and in this sense it is objective. According to Kragh's approach (Kragh, 1998: 241), knowledge about the boiling point of water belongs in the body of objective knowledge, in the sense that all scientists have agreed upon it. It is not "frontier science", meaning controversial fields of science which they have not been widely tested and accepted. Such fields are those in which scientific investigation is still underway and consensus has yet to be attained.

The authors of the AAAS' Project 2061 Benchmarks recognise that the study of science is an intellectual and social endeavour and have stated that "scientists in any one research group tend to see things alike, so even groups of scientists may have trouble being entirely objective about their methods and findings. For that reason, scientific teams are expected to seek out the possible source of bias in the design of their investigation and in their data analysis. Checking each other's results and explanations helps but that is no guarantee against bias" (AAAS, 1993: 8). In other words, although they do not mention explicitly, they accept the presence of individual's bias and propose checking each other's results or peer reviewing as a means of reducing bias though not eliminating it. They propose control and checking between research groups' work in order for the subjectivity of science to be decreased, in virtue of its objectivity.

A more explicit approach to objectivity comes from Ziman. He supports the view that scientists must produce objective knowledge, in the sense that research should not be directed towards making money or meeting social needs. He claims that "objectivity is what makes science so valuable in society... It is because it has a well-deserved reputation for impartiality in material reasons" (Ziman, 1996: 752). Ziman attributes the work of keeping science objective to the scientists who must not direct their researches towards making profit or personal glory. In other words, Ziman defends the objectivity of science in terms of impartiality.

Kimball's view on objectivity in science is clear in his description of NoS. Although the description is a little bit old-fashioned, it is consistent with the modern literature's "picture of the nature of science". Kimball claims that "science has a unique attribute of openness, both openness of mind, allowing for willingness to change opinion in the face of evidence, and openness of the realm of investigation, unlimited by such factors as religion, politics, or geography" (Kimball, 1967: 112). Although he doesn't explicitly use the terms "objectivity" and "subjectivity", it is implied that it is a characteristic of science-unlike religion or politics—not to limit itself by personal beliefs. For Kimball, science asserts its objective character through its openness to new evidence and tests.

Our intention is not to provide an exhaustive reading of the views held on objectivity and subjectivity in science. We are simply attempting to indicate that there are numerous views on the subject. Although some of them are inclined to attribute subjectivity to scientific endeavour, while the others are inclined to support the objectivity of science in the sense of impartiality or general agreement, the distinction between the subjective character of the scientific process and the rather objective character of scientific knowledge is not clearly suggested. However, this begs a number of questions: is there a single answer appropriate and compatible with science education as to what objectivity means when referring to science? Terms such as truth, impartiality or lack of bias are some of the alternatives to objectivity, but are they informative enough in relation to the objectivity or subjectivity of scientific knowledge? We argue that science educators should come to a consensus on the topic, specifically in the sense of distinguishing the subjective character of scientific research from the rather objective character of scientific knowledge.

In fact, issues such as the objectivity and subjectivity of science are mainly philosophical and are open to dialogue for centuries. Philosophy of science provides the ground in order all factors that affect and are affected by science to be studied, discussed and elaborated.

\section{Philosophy of Science Perspective}

The philosophy of science literature includes an ongoing discussion on the issue of subjectivity and objectivity in science with more nuanced positions than the ones found in the science education literature. Philosophical views may shed light on the issues that concern science education and provide some alternative perspectives. The views below do not belong to a particular epistemological trend, but they are indicative of a wide range of philosophical perspectives. However, what objectivity amounts to is far from clear-cut even in philosophical 
writings.

\subsection{Philosophical Views}

In the philosophy of science, a rather outdated discussion on objectivity distinguishes between the "context of discovery" and the "context of justification in science". The gathering of evidence to support the theory and the issue of whether or not it does support the theory are all part of the context of justification, which was claimed to be value-free (Crasnow, 1993: 195). In other words, the processes involved in the making of discoveries during the pursuit of a research program may not be involved when the discoveries are checked, tested and critically evaluated (Phillips, 1990). Popper is one of the philosophers of science who sees this distinction as crucial for understanding objectivity in research (Popper, 1972). Philosophers of a more historicist orientation, such as Hanson, Kuhn and Feyerabend, have a different view on this distinction. According to them, the positivist distinction between the "context of discovery" and the "context of justification" does not make sense, given that what we discover very much depends on what theory we are in the process of justifying. Their common assertion is that the distinction is invalid because "the contexts overlap" (Bird, 2011). This lack of distinction therefore undermines the objectivity of science.

Another approach to objectivity in science is proposed by Grene, who advocates contextual objectivity as the only possible kind of objectivity. The term "contextual objectivity" expresses the idea of reflecting all sides of a phenomenon or situation while retaining the values, beliefs and sentiments of the target audience. In Grene's words, "contextual objectivity is a critical truth-seeking as practiced within a given social context" (Grene, 1987: 75). This sort of objectivity is strongly associated with Annis' historical realism: "From the fact that justification is relative to the social practices and norms of a group, it does not follow that they cannot be criticized or that justification is somehow subjective. The practices and norms are epistemic and hence have as their goals truth and the avoidance of error" (Annis, 1978: 217). According to Grene, everything depends on the context, both in the sense of context of inquiry and the sense of the context forced on us by the complex structure of the natural world.

The Standpoint Epistemological approach advocated by Marxists and Feminists, like Harding, is very different. Standpoint theories claim to represent the world from a particular socially-situated perspective that can lay a claim to epistemic privilege or authority (Anderson, 2011). In this context, the subject of knowledge, which is an individual knower or the scientific community, always appears in scientific accounts of nature and social life as part of the object of knowledge. According to Harding, this is because social factors influence every step of scientific inquiry: problem selection, hypothesis formation, data collection and so on. So the subject of knowledge, which is part of the society, must be considered as a part of the object of knowledge from the perspective of scientific method. According to Harding, the subjects/agents of such epistemologies need stronger standards for objectivity than those of older epistemologies. "Strong objectivity requires the subject of knowledge to be placed on the same critical, causal plane as the object of knowledge" (Harding, 1993: 69). In other words, when it comes to the question of objectivity, both the subjects and objects of knowledge have to be subject to scrutiny.

The philosophical views mentioned above provide us with a range of ideas about objectivity and subjectivity of science as expounded in the philosophical literature. As we clearly stated at the beginning of this paper, the objectivity discussed here primarily concerns the epistemological dimension of the term. Though implicitly, the objectivity of science is strongly related to its social character: one way or another, it is increased by open dialogue processes in the scientific community and by peer reviewing, both of which provoke its impartiality. In this vein and taking into account the views developed in science education documents, we propose the objectivity of science in terms of intersubjective agreement as a concept which could promote clarity in the field.

\subsection{Objectivity as Intersubjective Agreement}

A substantial amount of sophisticated views on the objectivity of science rely on the notion of intersubjectivity. In this spirit, acknowledging the social character of scientific activity, some have declared the openness of scientific dialogue as a necessary safeguard for the objectivity of the scientific knowledge produced. This idea is supported by philosophers espousing quite different epistemological perspectives, including Hempel, Nozick and Longino.

Hempel sees the objectivity of scientific inquiry as being depending upon whether "scientific procedures including theory choice" are "characterised by standards that do not depend essentially on purely idiosyncratic in- 
dividual factors". In the light of criticisms of logical empiricist views, Hempel proposes: "a relaxed but objectivist construal of methodological principles" according to which "science is... an objectivist enterprise where claims are subject to a critical appraisal in terms of standards that are not simply subjective and idiosyncratic" (Hempel, 1983: 93). According to Hempel, "scientific objectivity is safeguarded by the principle that while hypotheses and theories may be freely invented and proposed in science, they can be accepted into the body of scientific knowledge only if they pass critical scrutiny" (Hempel, 1966: 16). Such "scrutiny" includes careful observations and experiments conducted by other members of the scientific community. Hempel recognizes the existence of science's epistemological values while at the same time defending its objectivity. In his own words “... scientific inquiry can be characterized by methodological principles which, while reflecting epistemological values, impose on scientific procedures and claim certain constraints of an objectively oriented, though partially vague, kind that preclude a view of science as an enterprise in which 'anything goes'” (Hempel, 1965: 391).

Nozick's view has some features in common with Hempel's. Nozick accepts that in the making of science there are a lot of complicating factors, meaning all those elements that impact on the scientific process, including theory choice, underdetermination of theories and the scientific tradition in which a certain investigation takes place: the so-called "paradigm". In his own words: "The complicating factors play a role in the advance of science. They contribute to the progress of science, to science's rationality and objectivity” (Nozick, 2001: 106). Nozick goes one step further by claiming that science is rational and objective, not despite the "complicating factors" but, in part, because of them. In brief, although these complicating factors are traditionally supposed to contaminate the objectivity of science, Nozick attributes a different role to them: the role of revealing certain characteristics and developing science.

In fact, Nozick claims that "science will be objective when no extraneous factor diverts it from accurately finding out the truth” (Nozick, 2001: 117). Acknowledging the existence of the complicating factors, he claims that they undoubtedly divert science, but we cannot determine what bias a given factor introduces without knowing the precise role it plays in the overall process. To be more specific, Nozick suggests that there are two ways in which science can reduce its objectivity: by accepting false statements or by failing to accept true ones. Since science is not infallible and complete, how can it be objective? Science might be self-correcting in overcoming particular biases for particular theories. In the case that some particular bias continues to operate, then it would interfere significantly with the objectivity of science. But what usually happens is that multiple biasing factors influence science at the same time, dragging it in different directions and resulting in a self-correcting mechanism. Nozick concludes that this results in a range of objectivity rather than a black and white situation. In this vein, the complicating factors may at different times support or weaken the objectivity of science.

Longino's view is both informative and in line with the view we proposed for science education. It is expressed through her Critical Contextual Empiricism (CCE) in which she attempts to integrate social context, scientific activity and objectivity. She argues that science is objective due to the fact that it is a social activity and therefore a public activity (Longino, 1990). Publicity therefore becomes the key to understanding the sense in which science is objective. For the public nature of the scientific process gives rise to a critical transformation which enhances its objectivity. This criticism limits the role of idiosyncratic subjective elements in scientific knowledge. In her own words, "A method of inquiry is objective to the degree that it permits transformative criticism” (Longino, 1990: 76). Thus, it is critical practices institutionalized by scientific communities that often qualify science as objective. While the possibility of criticism does not totally eliminate subjective preferences either from an individual or from a community's practice of science, it does provide a means for monitoring and assessing its influence in the formation of scientific knowledge (Longino, 1990: 73).

The three philosophers support the idea that the objectivity of science derives from intersubjective agreement between the members of a scientific community, which is the result of critical transformation of scientific knowledge and the self-correcting character of science through continuous testing. Despite the fact that in the making of science it is usually difficult to discern the end of the process and the start of the product, and although idiosyncratic factors may play a role at the start of the scientific research, the scientific products are characterized by a certain degree of impartiality and objectivity. This is what we suggest for science education. Objectivity of science in terms of intersubjective agreement provides students and teachers with a rather realistic image of science: social processes that embed a subjective character and the correspondent scientific product that is rather objective due to critical transformation. In the next section an episode from the history of science is proposed for highlighting and providing instruction in the issue. 


\section{Gilbert's Work on Electricity: From History of Science to Teaching Nature of Science}

Gilbert's De Magnete was published in 1600, a time when the Renaissance era dovetailed with the beginnings of the scientific revolution. Gilbert's writings reveal an intimate knowledge of the methods employed by navigators and other craftsmen of his days. In Gilbert's era, experimentation was generally confined to workmen and craftsmen and not to respectable scholars. In this context, Gilbert was one of those who began to bridge the gap between scholar and experimenter, contributing to the making of a new scientific context, a context which synthesized logic and experiment and would soon became known as the New Experimental Philosophy. Regarding the cultural and scientific context, it should be noted that the $17^{\text {th }}$ century saw two new and important elements entering the scientific enterprise: formal organizations of scientists, and periodical publications for the dissemination of scientific information. The latter half of the century witnessed the foundation of the Royal Society of London for Improving Natural Knowledge in England and the Royal Academy of Sciences in France. About the same time, the Royal Society of London licensed the publication of its Philosophical Transactions, thereby opening the way for communication and criticism among the scientific community (Roller \& Roller, 1957: 559).

Gilbert, a scientist of his era, tried to strike a balance between the modern spirit of experimentation and the medieval spirit of speculation (Boas, 1951). According to some historians, Gilbert was both an experimenter and a speculator, while for others he was both an empirical scientist and a metaphysician (Hesse, 1960). He showed clearly how science could be fruitfully pursued and how futile much of the work published up to that point had been, work published by authors who simply read what other people had written over the centuries about phenomena which no one had ever bothered checking. Thus, in his introduction to De Magnete Gilbert writes: "To you alone, true philosophers, ingenuous minds, who not only in books but in things themselves look for knowledge, have I dedicated these foundations of magnetic science” (Gilbert, 1600).

On the other hand Gilbert allowed his theoretical prejudices to colour his experimental reports and hence the conclusions he drew from them (Hesse, 1960). One such prejudice was his insistence on the non-existence of electric repulsion on the grounds that "All electrics attract objects of every kind; they never repel or propel" (Gilbert, 1600: 176); seemingly, electric repulsion did not match his conceptual scheme of things. His explanation of electrical attraction had its origins in moistness. He assumed that an "electric" when rubbed emits a material effluvium. He concluded that in electrical attraction the electric and the attracted body are united by the effluvium: "The electrical effluvia spread in all directions... And, as if they were material rods, they take up and hold straws, chaff and twigs, until their force is spent or vanishes...” (Roller \& Roller, 1957). The view that if one body exerts a force upon another there must be some material connection between them was commonly held in Gilbert's day. Action at a distance was a type of reversion to the sort of mysticism and magic from which scientists were trying to break free. It must have been due to his conceptual scheme that Gilbert failed to "discover" electrical repulsion although he must have observed its effects many times. He noticed that objects coming into contact with an excited electric are likely to fall away from it to the ground, but he believed this to be solely due to the force of the effluvium being spent or vanished. Although he possessed much more equipment than was required to observe the phenomena, his limiting hypothesis left no room for repulsion between electrics.

There is at least one more episode from Gilbert's work on electricity and magnetism that reveals Gilbert's theoretical commitments. It is his careful insistence on distinguishing between the force of attraction exerted by electrics on light bodies and magnetic coition in which bodies "run together with mutual forces". The reason for that insistence lies in his animism, speculation or personal beliefs. In spite of the apparent modernity of his work, Gilbert held on to an animistic notion of the physical world, perceiving magnetism as the "soul” of the planet. He wished to maintain that lodestone and iron and their properties are alone fundamental and predominant powers in the universe. Although the distinction between electric and magnetic forces was scientifically accepted, his insistence on the non-mutuality of electric forces needed scrutiny by the "scientific community".

At the same time, a thorough experimenter, Gilbert strove and managed to separate facts from fictions, as his lasting achievements demonstrate. Some of Gilbert's ideas were widely accepted by the scientific community of his time and withstood peer criticism. To begin with, he was the first to coin the term "electricity”, opening the way for new ideas and facilitating explanations (Roller \& Roller, 1957). Moreover, he was the first to classify materials into two categories: electrics and non-electrics; to use the terms "electric force” and "electric attraction" and to distinguish between magnetic and electric forces. And all these he did through experimentation. In the 
course of conducting his experiments, he found that the attracting force increases as the distance between the electric and the attracted body decreases. Moreover, Gilbert did remarkable work on the methodology of science, examining earlier hypothesis and framing new ones, introducing an experimental methodology into electricity and magnetism.

Some of Gilbert's ideas and findings were embraced by the scientific community of his times and evolved in the light of new experiments, hypothesis and interpretation. In writing up his own work, he successfully described all his work so it would be open to confirmation by others. In fact, it is fairly accurate to say that his work constitutes the foundations of modern electromagnetic theory. Those aspects of Gilbert's work that survived peer review and continuous testing exemplify the objective character of the scientific product. Scientists, no matter what their values are and what they believe-whether they be Orthodox, Catholic, Marxist, or communists-have accepted some of Gilbert's scientific products as true or approximately true.

Gilbert's methodology and work did not yield a modern scientific theory, but they did get closer to one than all previous work on electricity and magnetism. Both were strongly influenced by the socio-cultural milieu of the Renaissance and the Middle Ages as well as personal constraints. Gilbert, his work and the contradictory methodological approach he took to it, illustrate the issues we are concerned with here: socio-cultural influences on scientific practice and the rather objective-meaning impartial—character of scientific knowledge. A teaching and learning sequence based on this historical episode has been designed to instruct student teachers.

Asserting a prominent role for the history of science in science teaching (Matthews, 1989; Irwin, 1997; Solomon, Duveen, Scot, \& McCarthy, 1992), we use Gilbert's work on electricity both as a case study and a means of instruction. We propose it as appropriate for highlighting and instructing the ongoing philosophical debate on the subjectivity of scientific processes and the objectivity-primarily in the sense of the intersubjectivity —of scientific knowledge. Gilbert's work includes a number of features that illustrate critical interaction between the members of a community in a certain historical context.

Regarding our approach to teaching the NoS, we adopt the historically contextualized explicit-reflective approach (Abd-El-Khalick \& Akerson, 2004) in which "explicit" means the topic is dealt with directly and not left to emerge implicitly through exposure to other related concepts and "reflective" means that the method used includes iterative opportunities for the learners to test out, receive feedback on and revise their originally held ideas about the NoS. Finally, "historically contextualized" means that the topic is taught within a specific, relevant historical context. To these ends, we have used parts of Gilbert's work on electricity.

School science is a consensual body of knowledge. This knowledge is objective in the sense that the scientific community has determined its validity after extended open criticism. Of course, as researchers in the field of science education suggest, students should have the opportunity to see that there is also a subjective element in the practice of science. Science has its mechanisms - crucially, peer review and critical transformation-for ensuring that such subjective biases are limited. Our aim is to draw attention to the differences between the scientific process, which includes subjective elements, and the scientific output, which is arguably objective, providing for a better understanding of the NoS in the context of science education. The concept of intersubjectivity which premises peer reviewing and critical transformation in order for multiple "subjects" to agree upon a certain topic, seems to constitute a context for such an understanding.

At the start, students let us know their views on the topic. Contextualization followed using secondary sources (Ladyman, 2002; Rossi, 2001) which provided students with the big picture of Gilbert's era, meaning information about social conditions and crucial methodological issues. Adequate questions are posed in order for student teachers to recognize the social and personal factors that may have influenced Gilbert's work. Excerpts from De Magnete followed which focused on Gilbert's experiments regarding the classification of materials as "electric" and "non-electric" and the distinction between electric and magnetic forces. Students were strenuously encouraged to recognize that some of Gilbert's ideas and conclusions survived in their initial form, while others developed due to the criticism they received from subsequent scientists. The social face of science was revealed, where its sociality is reflected in the communication between scientists and communities. Moreover, students came to the conclusion that peer review, openness to dialogue and continuous testing make science impartial and objective, despite the factors that may influence it. Students were also encouraged to apply their new mental frames to additional real-world contemporary issues in order to see how science works or should work in our era.

\section{Conclusion}

In this paper, we have not set out to provide the ultimate contribution to the discussion regarding objectivity and 
subjectivity in science. Instead, we have argued that science education should become aware of the ongoing philosophical discussion if it is to prevent students' and teachers' views of science and scientific practice being biased and incomplete.

Objectivity and subjectivity in science are an issue upon which numerous philosophers and researchers within science education community have expressed their views. The concept of intersubjectivity, which emerged from the field of epistemology, relates to objectivity of science and can shed light on science education. Intersubjectivity is the idea which premises peer reviewing and critical transformation as a means of allowing a number of different subjects to agree upon a certain topic. In this way, the sociality of the research is assured and the objectivity of the output is increased. Such an approach seems to be helpful in clearing some of the notions of objectivity and subjectivity of science in science education literature and practice. Science is to a certain degree objective, not in spite of its sociality but because of it. This fits with the wider picture of science, according to that science is culturally and socially influenced while simultaneously seeking to decrease impartiality and bias through its practices. This certain framework of subjectivity and objectivity is proposed for teaching via a historical episode, namely Gilbert's work on electricity. Gilbert's methodological approach and the outcomes of this approach seem to be appropriate for familiarizing student teachers with the NoS in general and objectivity of science in particular.

\section{References}

Abd-El-Khalick, F., \& Akerson, V. (2004). Learning as Conceptual Change: Factors Mediating the Development of Preservice Elementary Teachers' Views on Nature of Science. Science Teacher Education, 88, 785-810. http://dx.doi.org/10.1002/sce.10143

American Association for the Advancement of Science (AAAS) (1993). Project 2061: Benchmarks for Science Literacy. New York: Oxford University Press. http://www.project2061.org/publications/bsl/online/index.php

Anderson, E. (2011). Feminist Epistemology and Philosophy of Science. http://plato.stanford.edu/entries/feminism-epistemology/\#standpoint

Annis, D. (1978). A Contextualist Theory of Epistemic Justification. American Philosophical Quarterly, 15, $213-219$. http://www.jstor.org/stable/20009716

Bird, A. (2011). Thomas Kuhn. http://plato.stanford.edu/entries/thomas-kuhn/

Boas, M. (1951). Bacon and Gilbert. Journal of the History of Ideas, 12, 466-467. http://dx.doi.org/10.2307/2707755

Burbules, N., \& Linn, M. (1991). Science Education and Philosophy of Science: Congruence or Contradiction? International Journal of Science Education, 13, 227-242. http://dx.doi.org/10.1080/0950069910130302

Crasnow, S. (1993). Can Science Be Objective? Longino’s Science as Social Knowledge. Hypatia, 8, 194-201. http://dx.doi.org/10.1111/j.1527-2001.1993.tb00045.x

Curriculum Development and Supplemental Materials Commission (2004). Science Framework for California Public Schools. Sacramento: California Department of Education.

Duschl, R. (1990). Restructuring Science Education: The Importance of Theories and Their Development. New York: Teachers College, Columbia University.

Eflin, J., Glennan, S., \& Reisch, G. (1999). The Nature of Science: A Perspective from the Philosophy of Science. Journal of Research in Science Teaching, 36, 107-116. http://dx.doi.org/10.1002/(SICI)1098-2736(199901)36:1<107::AID-TEA7>3.0.CO;2-3

Gilbert, W. (1600/1958). De Magnete. New York: Dover Publications.

Grene, M. (1987). Ch. 3: Historical Realism and Contextual Objectivity: A Developing Perspective in the Philosophy of Science. In The Process of Science Contemporary Philosophical Approaches to Understanding Scientific Practice (pp. 69-81). Leiden: Martinus Nijhoff Publishers.

Harding, S. (1993). Ch. 3: Rethinking Standpoint Epistemology: What Is Strong Objectivity? In Feminist Epistemologies (pp. 49-82). New York and London: Routledge.

Heering, P. (1992). On Coulomb’s Inverse Square Law. American Journal of Physics, 60, 988-1000. http://dx.doi.org/10.1119/1.17002

Hempel, C. G. (1965). Aspects of Scientific Explanation and Other Essays in the Philosophy of Science. New York: Free Press.

Hempel, C. G. (1966). Philosophy of Natural Sciences. Upper Saddle River, NJ: Prentice Hall.

Hempel, C. G. (1983). Ch. 4: Valuation and Objectivity in Science. In Physics, Philosophy and Psychoanalysis (pp. 73-100). 
Dordrecht: Springer Netherlands. http://dx.doi.org/10.1007/978-94-009-7055-7_4

Hesse, M. (1960). Gilbert and the Historians (I). The British Journal for the Philosophy of Science, 11, 1-10. http://dx.doi.org/10.1093/bjps/XI.41.1

Irwin, A. (1997). Historical Case Studies: Teaching the Nature of Science in Context. Science Education, 84, 5-26. http://dx.doi.org/10.1002/(SICI)1098-237X(200001)84:1<5::AID-SCE2>3.0.CO;2-0

Kimball, M. (1967). Understanding the Nature of Science: A Comparison of Scientists and Science Teachers. Journal of Research in Science Education, 5, 110-120.

Kragh, H. (1998). Social Constructivism, the Gospel of Science, and the Teaching of Physics. Science \& Education, 7 , 231-243. http://dx.doi.org/10.1023/A:1008645218507

Ladyman, J. (2002). Understanding Philosophy of Science. London: Routledge.

Lederman, N. G. (2007). Ch. 28: Nature of Science: Past, Present and Future. In Handbook of Research in Science Education (pp. 831-880). New York: Taylor \& Francis Group.

Lederman, N., \& Abd-El-Khalick, F. (2002). Ch. 5: Avoiding De-Natured Science: Activities that Promote Understandings of the Nature of Science. In The Nature of Science in Science Education, Rationales and Strategies (pp. 83-126). Netherlands: Kluwer Academic Publisher. http://dx.doi.org/10.1007/0-306-47215-5_5

Longino, H. (1990). Science as Social Knowledge. Princeton, NJ: Princeton University Press.

Matthews, M. (1989). A Role for History and Philosophy in Science Teaching. Interchange, 20, 3-15. http://dx.doi.org/10.1007/BF01807043

Matthews, M. (1993). Constructivism and Science Education: Some Epistemological Problems. Journal of Science Education and Technology, 2, 359-370. http://dx.doi.org/10.1007/BF00694598

McComas, W. (2002). The Nature of Science in Science Education: Rationales and Strategies. Netherlands: Kluwer Academic Publisher. http://dx.doi.org/10.1007/0-306-47215-5

McComas, W., Clough, M., \& Almazroa, H. (2002). Ch. 1: The Role and Character of the Nature of Science in Science Education. In The Nature of Science in Science Education, Rationales and Strategies (pp. 3-39). Netherlands: Kluwer Academic Publisher. http://dx.doi.org/10.1007/0-306-47215-5 1

Millar, R., \& Driver, R. (1987). Beyond Processes. Studies in Science Education, 14, 33-62. http://dx.doi.org/10.1080/03057268708559938

Ministry of Education (1993). Science in the New Zealand Curriculum. Wellington: Learning Media.

National Research Council (NRC) (1996). National Science Education Standards. Washington DC: The National Academy Press.

National Research Council (NRC) (2012). A Framework for K-12 Science Education: Practices, Crosscutting Concepts, and Core Ideas. Washington DC: The National Academies Press.

Next Generation Science Standards (NGSS) (2013). A Framework for K-12 Science Education: Practices, Crosscuting Concepts and Core Ideas. http://www.nextgenscience.org/

Nozick, R. (2001). Invariances: The Structure of the Objective World. London: The Belknap Press of Harvard University Press.

Osborne, J., Collins, S., Ratcliffe, M., Millar, R., \& Duschl, R. (2003). What “Ideas-about-Science” Should Be Taught in School? A Delphi Study of the Expert Community. Journal of Research in Science Teaching, 40, 692-720. http://dx.doi.org/10.1002/tea.10105

Phillips, D. (1990). Ch. 1: Subjectivity and Objectivity: An Objective Inquiry. In Qualitative Inquiry in Education: The Continuing Debate (pp. 19-37). New York: Teachers College Press.

Popper, K. (1972). Objective Knowledge: An Evolutionary Approach. Oxford: Clarendon Press.

Roller, D., \& Roller, H. D. (1957). Ch. 8: The Development of the Concept of Electric Charge: Electricity from Ancient Greeks to Coulomb. In Harvard Case Histories in Experimental Science (pp. 541-640). Cambridge, MA: Harvard University Press. http://dx.doi.org/10.4159/harvard.9780674598713.c5

Rossi, P. (2001). The Birth of Modern Science. Oxford: Willy.

Solomon, J., Duveen, J., Scot, L., \& McCarthy, S. (1992). Teaching about the Nature of Science through History: Action Research in the Classroom. Journal of Research in Science Teaching, 29, 409-421. http://dx.doi.org/10.1002/tea.3660290408

Ziman, J. (1996). Is Science Losing Its Objectivity? Nature, 382, 751-754. http://dx.doi.org/10.1038/382751a0 
Scientific Research Publishing (SCIRP) is one of the largest Open Access journal publishers. It is currently publishing more than 200 open access, online, peer-reviewed journals covering a wide range of academic disciplines. SCIRP serves the worldwide academic communities and contributes to the progress and application of science with its publication.

Other selected journals from SCIRP are listed as below. Submit your manuscript to us via either submit@scirp.org or Online Submission Portal.
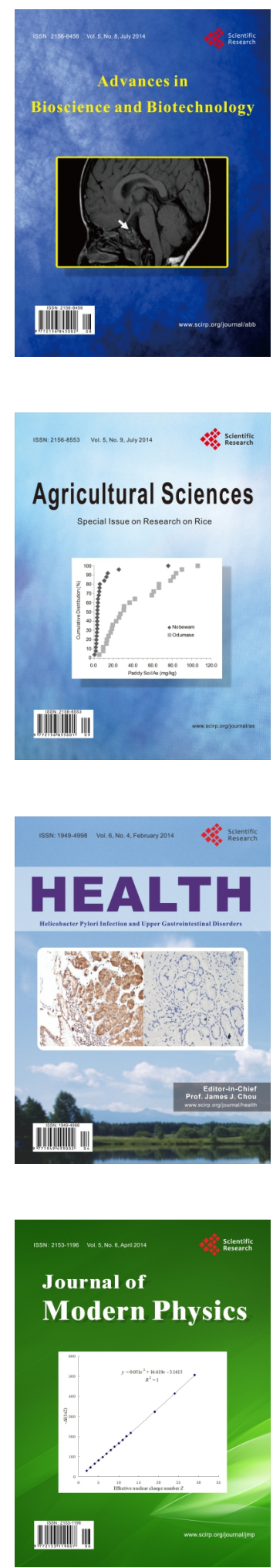
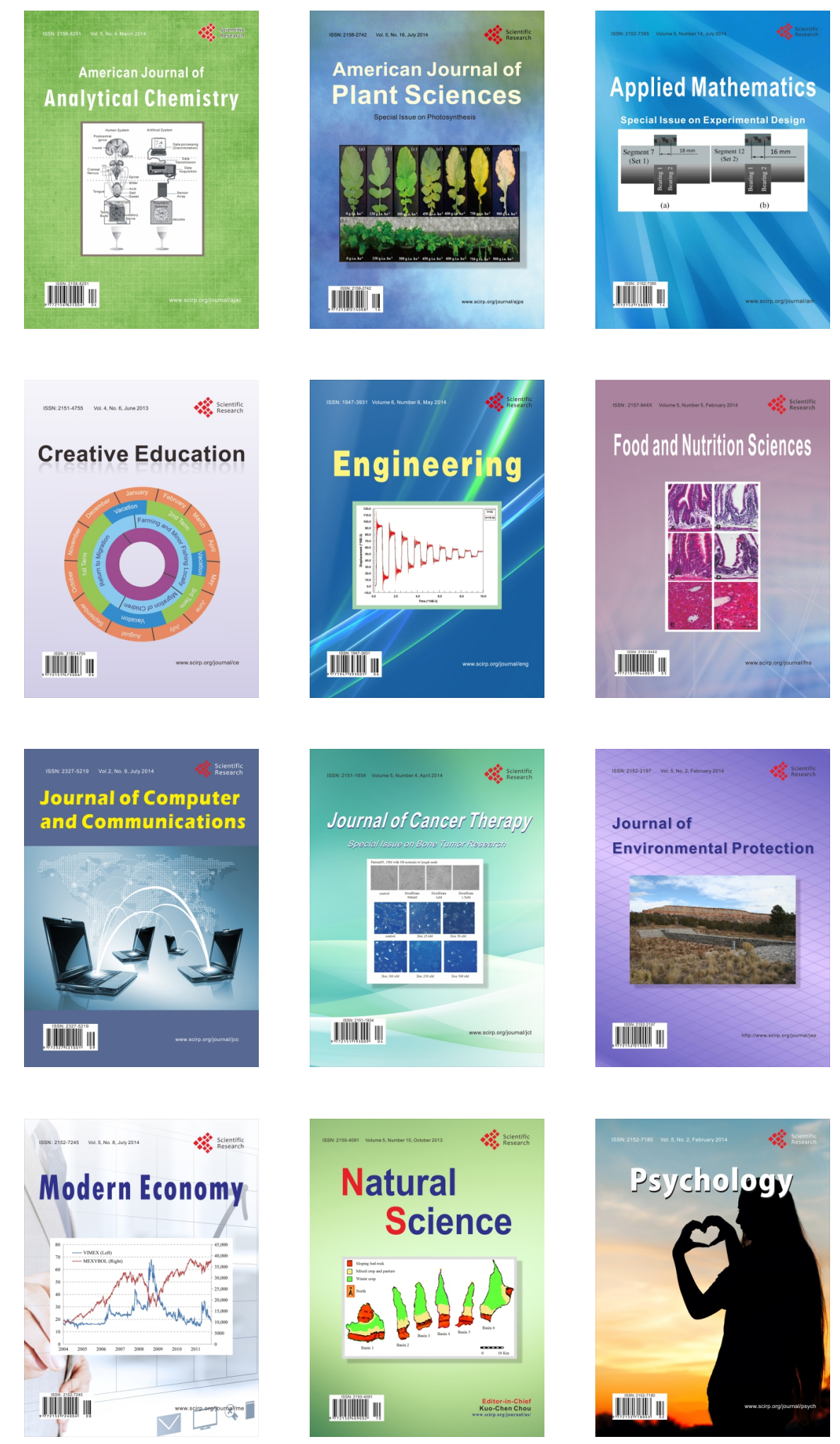